\title{
Decrease of Free Thyroxine Levels after Controlled Ovarian Hyperstimulation*
}

\author{
A. F. MUlleR, A. VERHOEFF, M. J. MANTEL, F. H. DE JONG, and A. BERGHOUT \\ Departments of Internal Medicine (A.F.M., A.B.), Obstetrics and Gynecology (A.V.), and Clinical \\ Chemistry (M.J.M.), Zuiderziekenhuis Rotterdam, 3075 EA Rotterdam, The Netherlands; and \\ Department of Internal Medicine III, University Hospital Dijkzigt (F.H.d.J.), 3015 GD Rotterdam, \\ The Netherlands
}

\begin{abstract}
Controlled ovarian hyperstimulation could lead to opposing effects on thyroid function. Therefore, in a prospective study of 65 women undergoing controlled ovarian hyperstimulation, thyroid hormones, $\mathrm{T}_{4}$-binding globulin, TPO antibodies, gonadotropins, estradiol, and PRL were measured before and after controlled ovarian hyperstimulation.

After ovarian stimulation (mean \pm SE of mean): free $\mathrm{T}_{4}$ decreased, $14.4 \pm 0.2$ vs. $12.9 \pm 0.2 \mathrm{pmol} / \mathrm{L}(P<0.0001)$; thyroidstimulating hormone increased, $2.3 \pm 0.3$ ss. $3.0 \pm 0.4 \mathrm{mU} / \mathrm{L}(P<$ $0.0001) ; \mathrm{T}_{4}$-binding globulin increased, $25.2 \pm 0.7$ vs. $33.9 \pm 0.9$ $\mathrm{mg} / \mathrm{L}(P<0.0001)$; total $\mathrm{T}_{4}$ increased, $98.1 \pm 2.3$ vs. $114.6 \pm 2.5$ $\mathrm{nmol} / \mathrm{L}(P<0.0001)$; total $\mathrm{T}_{3}$ increased, $2.0 \pm 0.04$ vs. $2.3 \pm 0.07$ $\mathrm{nmol} / \mathrm{L}(P<0.0001)$; TPO antibodies decreased, $370 \pm 233 \mathrm{U} / \mathrm{mL}$
\end{abstract}

vs. $355 \pm 224 \mathrm{U} / \mathrm{mL}(P<0.0001) ; \mathrm{LH}$ decreased, $8.1 \pm 1.1$ vs. $0.4 \pm$ $0.1 \mathrm{U} / \mathrm{L}(P<0.0001) ; \mathrm{FSH}$ did not change, $6.5 \pm 0.6$ vs. $7.9 \pm 0.9$ $\mathrm{U} / \mathrm{L}(P=0.08)$; human CG increased, $<2 \pm 0.0 \mathrm{vs} .195 \pm 16 \mathrm{U} / \mathrm{L}$ $(P<0.0001)$; estradiol increased, $359.3 \pm 25.9 \mathrm{pmol} / \mathrm{L}$ vs. $3491.8 \pm$ $298.3 \mathrm{pmol} / \mathrm{L}(P<0.0001)$; and $\mathrm{PRL}$ increased, $0.23 \pm 0.02 \mathrm{vs}$. $0.95 \pm 0.06 \mathrm{U} / \mathrm{L}(P<0.0001)$.

Because low maternal free $\mathrm{T}_{4}$ and elevated maternal thyroid-stimulating hormone levels during early gestation have been reported to be associated with impaired psychomotor development in the offspring, our findings indicate the need for additional studies in the children of women who where exposed to high levels of estrogens around the time of conception. (J Clin Endocrinol Metab 85: 545-548, 2000)
L OW MATERNAL free $\mathrm{T}_{4}\left(\mathrm{fT}_{4}\right)$ levels during early gestation are associated with impaired psychomotor development in infancy, persisting into childhood $(1,2)$.

During pregnancy, high estradiol $\left(\mathrm{E}_{2}\right)$ levels lead, through a rise in $\mathrm{T}_{4}$-binding globulin (TBG), to a transient drop in $\mathrm{fT}_{4}$ levels (3-5). Human CG (hCG) is known to exert a thyrotrophic action both in vitro and in vivo, best explained by the structural homology of thyroid-stimulating hormone (TSH) and hCG and their respective receptors (6). This explains why serum TSH does not rise during the first trimester but decreases reciprocally with the increase in hCG (5). Controlled ovarian hyperstimulation-for conventional in vitro fertilization (IVF) or intracytoplasmic sperm injection (ICSI) — could, therefore, lead to opposing effects on thyroid function: the thyrotrophic action of hCG could result in elevated $\mathrm{fT}_{4}$ levels; alternatively, the induced rise in $\mathrm{E}_{2}$ could lead to a lowering of $\mathrm{fT}_{4}$.

The aim of the present study was to determine the acute effects of controlled ovarian hyperstimulation on thyroid function. We, therefore, designed a prospective study of women undergoing controlled ovarian hyperstimulation.

\section{Materials and Methods}

We studied 65 of 177 women who previously participated in a prospective study on thyroid autoimmunity and abortion (7). The study was

Received April 29, 1999. Revision received October 7, 1999. Accepted October 22, 1999.

Address correspondence and requests for reprints to: A. F. Muller, M.D., Department of Internal Medicine III, University Hospital Dijkzigt, Dr. Molewaterplein 40, Room D438, 3015 GD, Rotterdam, The Netherlands. E-mail: muller@inw3.azr.nl.

* Data presented in part at the 24th Annual Meeting of the European Thyroid Association, Munich, Germany, August 30-September 3, 1997. approved by the hospital ethics committee, and all subjects gave informed consent at initial presentation.

Our IVF program has been described in detail previously (8). Ovarian stimulation consisted of a 1-mg GnRH-analog sc or intranasally from cycle day 1 to days 10-12, 225 IU human menopausal gonadotrophin (hMG) im from day 3 to days 9-11, and 10,000 IU hCG im 35 h before follicle puncture. Follicle growth was assessed by ultrasound from day 10. Follicle puncture was done on day 14 in the majority of women. There was no difference in controlled ovarian hyperstimulation in those receiving ICSI and conventional IVF. Blood was drawn at random during the menstrual cycle from all women at their initial visit and after ovulation induction immediately before or after transvaginal follicle puncture. After the initial visit, TSH was determined immediately, whereas all other assays were done from frozen samples $(-70 \mathrm{C})$.

To investigate assay cross-reactivity, one ampoule hMG $(75,000 \mathrm{U} / \mathrm{L})$ was diluted in saline to $75 \mathrm{U} / \mathrm{L}$. In this solution TSH and hCG were measured.

\section{Assays}

TSH, total $\mathrm{T}_{3}, \mathrm{fT}_{4}, \mathrm{FSH}, \mathrm{LH}, \mathrm{hCG}$ (total and $\beta$ ), and PRL were determined with an immunoluminometric assay (Chiron Corp., East Walpole, MA). Reference ranges were: TSH, $0.2-4.5 \mathrm{mU} / \mathrm{L}$; total $\mathrm{T}_{3}, 1.3-2.8$ $\mathrm{nmol} / \mathrm{L}$; $\mathrm{fT}_{4}, 9-22 \mathrm{pmol} / \mathrm{L}$; and PRL, 0.03-0.63 U/L. Total $\mathrm{T}_{4}$ was determined with a in-house RIA with a reference range of $64-132 \mathrm{nmol} / \mathrm{L}$. TBG was determined with a RIA (Brahms, Berlin, Germany). Estradiol was determined with a RIA (Diagnostic Product Corporation, Los Angeles, CA). TPO antibodies were determined with a RIA (Henning Berlin GmbH \& Co., Berlin, Germany).

\section{Statistics}

Qualitative data between groups were tested using the $\chi^{2}$ test. Data on hormones and antibodies were analyzed by the Wilcoxon matchedpairs signed-ranks test; correlations are given as Spearman's rank correlation coefficient (all $P$ values are two-sided). $P$ values of less than 0.05 were considered significant. Data are presented as mean $\pm \mathrm{SE}$ of mean. 


\section{Results}

\section{General data}

There were no differences in age, cause of infertility, thyroid function, family history of thyroid disease, smoking behavior (Table 1), number of previous pregnancies and deliveries or spontaneous abortions between study subjects and those who did not consent to repeated blood sampling (nonparticipants). None of the study subjects used thyroid medication.

\section{Thyroid function and TPO antibodies}

After ovarian stimulation: $\mathrm{fT}_{4}$ decreased, (before $v s$. after) $14.4 \pm 0.2 \mathrm{pmol} / \mathrm{L}$ vs. $12.9 \pm 0.2 \mathrm{pmol} / \mathrm{L}(P<0.0001)$ (Fig. 1); total $\mathrm{T}_{4}$ increased, $98.1 \pm 2.3 \mathrm{nmol} / \mathrm{L}$ vs. $114.6 \pm 2.5$ $\mathrm{nmol} / \mathrm{L}(P<0.0001)$; total $\mathrm{T}_{3}$ increased, $2.0 \pm 0.05 \mathrm{nmol} / \mathrm{L}$ vs. $2.3 \pm 0.07 \mathrm{nmol} / \mathrm{L}(P<0.0001)$; TBG increased, $25.2 \pm 0.7$ $\mathrm{mg} / \mathrm{L}$ vs. $33.9 \pm 0.9 \mathrm{mg} / \mathrm{L}(P<0.0001) ; \mathrm{TSH}$ increased, $2.3 \pm$ $0.3 \mathrm{mU} / \mathrm{L}$ vs. $3.0 \pm 0.4 \mathrm{mU} / \mathrm{L}(P<0.0001)$ (Fig. 2$)$; and $\mathrm{TPO}$ antibodies decreased, $370 \pm 233 \mathrm{U} / \mathrm{mL}$ vs. $355 \pm 224 \mathrm{U} / \mathrm{mL}$ (median, $57 \mathrm{U} / \mathrm{mL}$ and $44 \mathrm{U} / \mathrm{mL}$, respectively) $(P<0.0001)$.

In those women receiving ICSI, $\mathrm{fT}_{4}$ was slightly, but significantly, higher after ovarian hyperstimulation compared with women receiving conventional IVF: $13.7 \pm 0.4 \mathrm{pmol} / \mathrm{L}$ vs. $12.6 \pm 0.3 \mathrm{pmol} / \mathrm{L}(P<0.05)$.

Gonadotropins, $E_{2}$, and PRL

After ovarian stimulation: $\mathrm{LH}$ decreased, $8.1 \pm 1.1 \mathrm{U} / \mathrm{L}$ vs. $0.4 \pm 0.1 \mathrm{U} / \mathrm{L}(P<0.0001) ; \mathrm{FSH}$ did not change, $6.5 \pm 0.6 \mathrm{U} / \mathrm{L}$ vs. $7.9 \pm 0.9 \mathrm{U} / \mathrm{L}(P=0.08) ; \mathrm{E}_{2}$ increased, $359.3 \pm 25.9$ $\mathrm{pmol} / \mathrm{L}$ vs. $3491.8 \pm 298.3 \mathrm{pmol} / \mathrm{L}(P<0.0001)$; hCG increased, less than $2 \pm 0.0 \mathrm{U} / \mathrm{L}$ vs. $195 \pm 16 \mathrm{U} / \mathrm{L}(P<0.0001)$; and PRL increased: $0.23 \pm 0.02 \mathrm{U} / \mathrm{L}$ vs. $0.95 \pm 0.06 \mathrm{U} / \mathrm{L}(P<$ $0.0001)$

\section{Correlations}

A significant correlation exists between the increase in $\mathrm{E}_{2}$ and the increase in TBG (Fig. 3) and total $\mathrm{T}_{4} ; \mathrm{r}=0.50, P<$

TABLE 1. General data
0.0001 and $r=0.73, P<0.0001$, respectively. The increase in TBG was significantly correlated with the decrease in $\mathrm{fT}_{4} ; \mathrm{r}=$ $-0.26, P<0.05$ (Fig. 4).

\section{Assay cross-reactivity}

In the saline containing $75 \mathrm{U} / \mathrm{L} \mathrm{FSH}$ and LH (hMG), TSH and hCG levels were, respectively, $0.02 \mathrm{mU} / \mathrm{L}$ and $12 \mathrm{U} / \mathrm{L}$, indicating that the gonadotropins did not contribute significantly to the levels of TSH and hCG estimated after ovulation induction.

\section{Discussion}

In this prospective study, we found controlled ovarian hyperstimulation to lead to a lowering of $\mathrm{fT}_{4}$ levels concom-

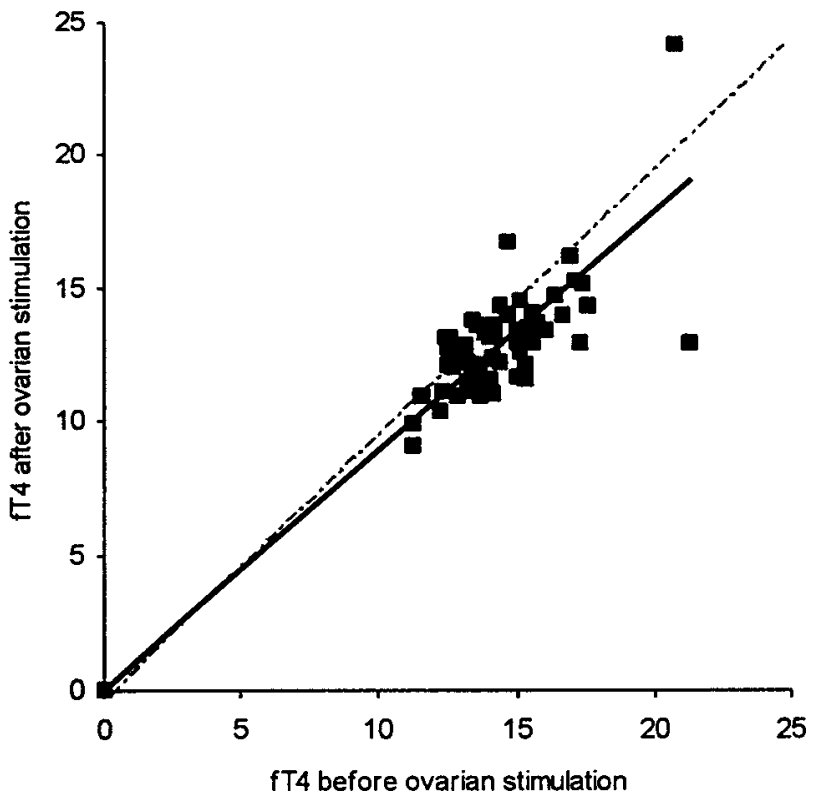

FIG. 1. $\mathrm{fT}_{4}$ levels before and after ovarian stimulation.

\begin{tabular}{|c|c|c|c|}
\hline Variable & $\begin{array}{l}\text { Study subjects } \\
(\mathrm{n}=65)\end{array}$ & $\begin{array}{l}\text { Nonparticipants } \\
\quad(\mathrm{n}=112)\end{array}$ & $\mathrm{P}$ value \\
\hline Mean (土SEM) TSH level (mU/L) $)^{a}$ & $2.3 \pm 0.3$ & $1.8 \pm 0.1$ & NS \\
\hline Median TSH level (mU/L) ${ }^{a}$ & 1.65 & 1.65 & NS \\
\hline \multicolumn{4}{|l|}{ No. of patients (\%) with indicated TSH level } \\
\hline$<0.20$ & $2(3)$ & $4(4)$ & NS \\
\hline$\geq 0.2-\leq 4.5$ & $59(91)$ & $102(91)$ & NS \\
\hline$>4.5$ & $4(6)$ & $4(4)$ & NS \\
\hline Mean $( \pm \mathrm{SD})$ age $(\mathrm{yr})$ & $32.7 \pm 4.0$ & $32.1 \pm 4.4$ & NS \\
\hline \multicolumn{4}{|l|}{ No. of patients with indicated cause of infertility $(\%)^{b}$} \\
\hline Male infertility or fallopian tube obstruction & $44(68)$ & $72(64)$ & NS \\
\hline Endometriosis & $4(6)$ & $7(6)$ & NS \\
\hline PCOS & $4(6)$ & $7(6)$ & NS \\
\hline Idiopathic & $13(20)$ & $24(21)$ & NS \\
\hline No. of patients with a family history of thyroid disease $(\%)^{c}$ & $7(11)$ & $13(12)$ & NS \\
\hline No. of patients who smoke $(\%)^{d}$ & $16(25)$ & $44(39)$ & NS \\
\hline No. of patients who underwent conventional IVF & $49(75)$ & $77(69)$ & NS \\
\hline No. of patients who underwent ICSI & $16(25)$ & $35(31)$ & NS \\
\hline
\end{tabular}

PCOS, Polycystic ovary syndrome.

a TSH level not determined in two nonparticipants.

${ }^{b}$ Cause of infertility unknown in two nonparticipants.

${ }^{c}$ Family history of thyroid disease unknown in two nonparticipants.

${ }^{d}$ Smoking behavior unknown in three women, one of whom was a participant. 


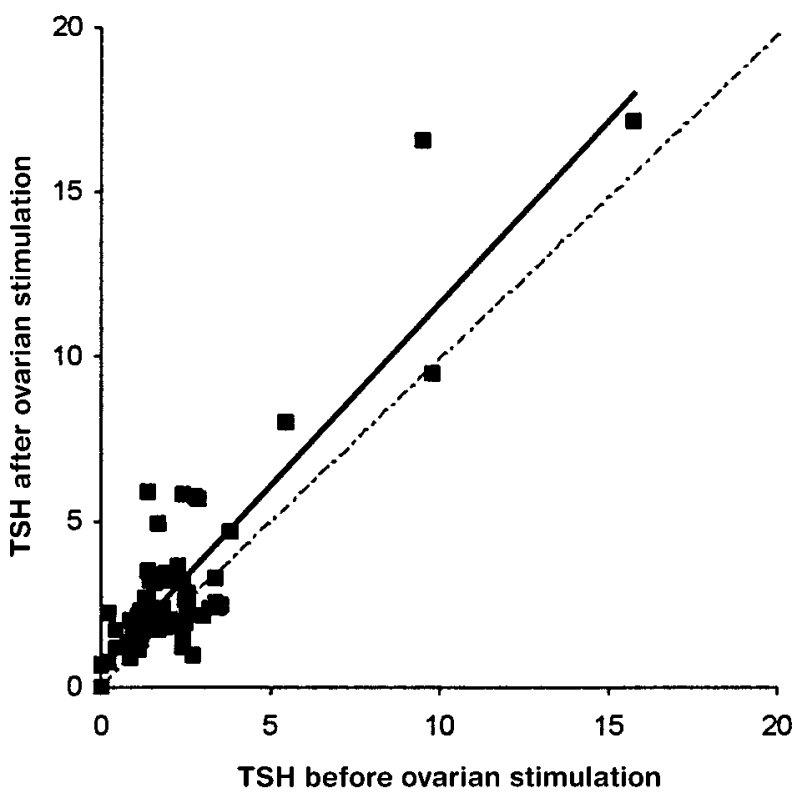

FIG. 2. TSH levels before and after ovarian stimulation.

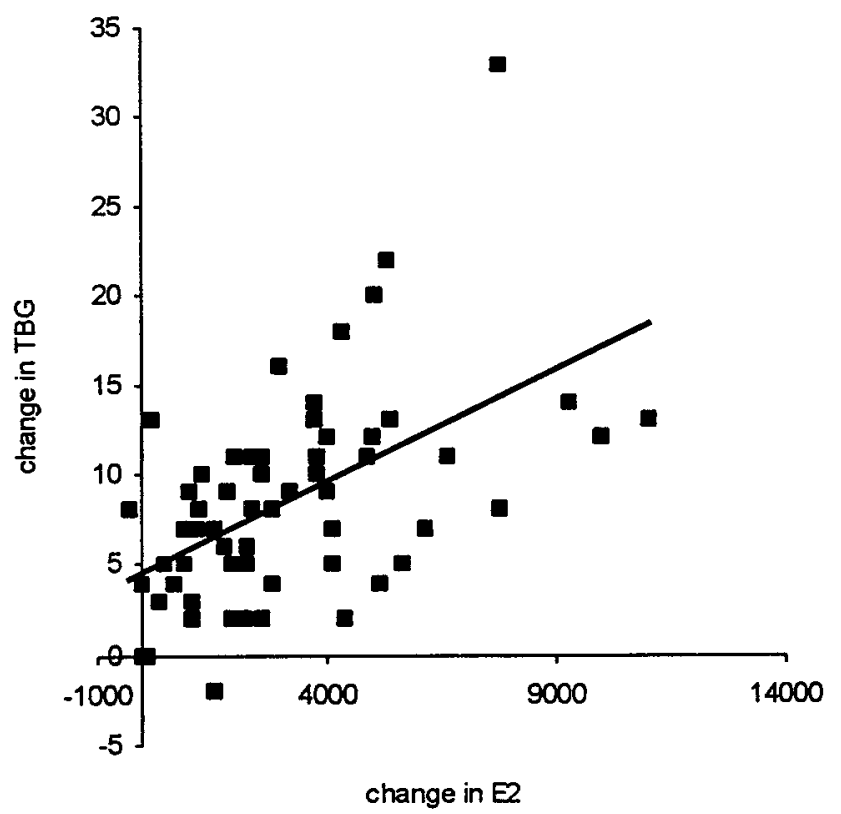

FIG. 3. Change in $\mathrm{E}_{2}$ vs. change in TBG.

itant with a rise in TSH, indicating decreased $\mathrm{T}_{4}$ availability at the tissue level at the time of follicle puncture. This increase in TSH is in contrast with the generally observed decrease in TSH during the first trimester of pregnancy (3-5). The possible significance of these findings lies in the recently described association between maternal thyroid status and subsequent neuropsychological development of the child $(1,2)$. Pop et al. (1) found $\mathrm{fT}_{4}$ levels within the lowest 10 th percentile at 12 weeks gestation in apparently healthy women to be associated with impaired psychomotor development at 10 months of age in their offspring. That these differences persist into childhood has very recently been shown by Haddow et al. (2), who provide evidence that children born from mothers with hypothyroidism during the second trimester of

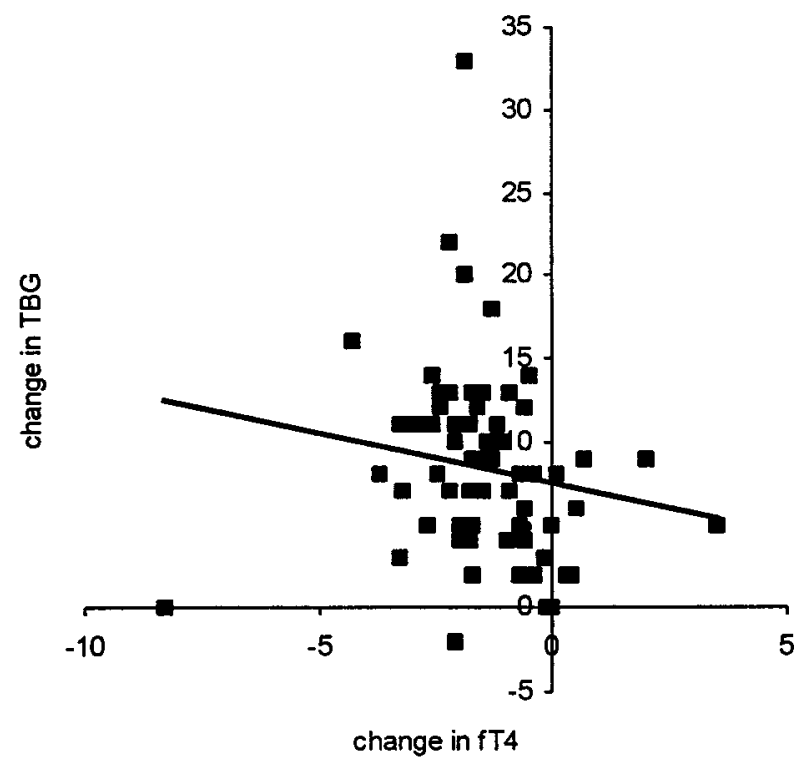

Fig. 4. Change in $\mathrm{fT}_{4}$ vs. change in TBG.

pregnancy have lower IQ scores and more school problems at 7-9 yr of age than children born from mothers who were euthyroid during pregnancy. These studies provide compelling evidence that even relatively mild disturbances in maternal thyroid function can lead to persistent and clinically relevant impairment in neuropsychological performance.

Animal, as well as human, studies have shown that due to the inability of the fetal thyroid to produce thyroid hormone during early pregnancy the maturing brain is totally dependent on maternal supply of thyroid hormone (9-12), thus, offering an explanation for the association between low maternal $\mathrm{fT}_{4}$ levels and impaired psychomotor development in the offspring.

Ovarian hyperstimulation leads to hyperestrogenism, which in turn leads to increased TBG levels (for review see Ref. 3) and, therefore, to a decrease in $\mathrm{fT}_{4}$ (3). During early pregnancy, some degree of thyroid stimulation by hCG exists; in some women this can give rise to gestational hyperthyroidism $(3,6)$. In molar pregnancy or chorionic carcinoma severe hyperthyroidism may even be the presenting symptom $(6,13,14)$. Apparently, the hCG administration as applied during ovarian hyperstimulation is too short and/or too low-dosed to counterbalance the opposing effect of increased $\mathrm{T}_{4}$ binding.

It might be argued that thyroid function at baseline was influenced by the phase of the menstrual cycle. However, it has been shown previously that thyroid function is unchanged during the follicular and luteal phases (5). Another possible source of bias could be assay interference. However, we found only negligible cross-reactivity. Moreover, during ovarian hyperstimulation, PRL (a polypeptide hormone) increased significantly and this change was near significantly correlated with the rise in TSH (a glycoprotein hormone); $\mathrm{r}=$ $0.22, P=0.09$, indicating a pituitary source of TSH and not assay cross-reactivity. Finally, we only measured TBG, whereas albumin and transthyretin can bind $\mathrm{T}_{4}$ as well. However, during pregnancy the fraction of $\mathrm{T}_{4}$ bound by TBG increases to more than $75 \%$, as compared to two thirds in a 
nonpregnant state (3). In addition, concomitantly with the rise in TBG, total $\mathrm{T}_{4}$ levels-measuring all bound $\mathrm{T}_{4}$-increased as well.

There is strong evidence that sex steroids can modulate Th1/Th2 cytokine balance in such a way that during pregnancy cell-mediated immune function and Th1 cytokine production are suppressed and humoral immunity and Th2 cytokine production are enhanced $(15,16)$. The significant decline in TPO titers argues against a role of thyroid autoimmunity in the lowering of $\mathrm{fT}_{4}$ levels during controlled ovarian hyperstimulation.

In several studies (17-22), no difference in the developmental outcome in children conceived by conventional IVF compared with non-IVF controls was found. However, in none of these studies maternal $\mathrm{fT}_{4}$ levels in early gestation were taken into consideration. When comparing children conceived by ICSI $(25 \%$ of our study subjects underwent ICSI) with children conceived by conventional IVF, there is an increased risk of developmental delay at $1 \mathrm{yr}$ of age in children conceived by ICSI (23). In our study, we found $\mathrm{fT}_{4}$ levels after ovarian hyperstimulation to be slightly higher in women who subsequently underwent ICSI compared with those who underwent conventional IVF.

In conclusion, we have found that ovarian hyperstimulation leads to a lowering of $\mathrm{fT}_{4}$ levels with a concomitant rise in TSH. These findings have potential implications for women whose $\mathrm{fT}_{4}$ levels are already in the lower range of normal before the start of ovarian hyperstimulation, especially if living in areas of iodine deficiency, with its relative hypothyroxinemia during pregnancy $(3,4)$. We hypothesize that if low maternal $\mathrm{fT}_{4}$ levels in early gestation lead to impaired psychomotor development further lowering, albeit only transiently, just before the period in which the developing brain is critically dependent on the maternal supply of $\mathrm{T}_{4}$ may amplify this effect. These results indicate the need for further research to determine whether the observed changes in $\mathrm{fT}_{4}$ levels will, indeed, lead to delayed psychomotor development in the offspring of women undergoing controlled ovarian hyperstimulation.

\section{Acknowledgments}

We are indebted to Mrs. I. Jongste and to the nursing staff of the gynecological outpatient clinic of the "Zuiderziekenhuis Rotterdam" for their assistance in the conduct of this study and to R. Docter for critical review of the manuscript. We acknowledge H. van Toorn and H. Marijnes for determining, respectively, TBG and $\mathrm{E}_{2}$. We are also very grateful for the help of R. Verwers and M. Neele for performing all other laboratory tests.

\section{References}

1. Pop VJ, Kuijpens JL, van Baar AL, et al. 1999 Low maternal fT4 concentrations during early pregnancy are associated with impaired psychomotor development in infancy. Clin Endocrinol. 50:149-155.

2. Haddow JE, Palomaki GE, Allan WC, et al. 1999 Maternal thyroid deficiency during pregnancy and subsequent neuropsychological development of the child. N Engl J Med. 341:549-555.

3. Glinoer D. 1997 The regulation of thyroid function in pregnancy: pathways of endocrine adaptation from physiology to pathology. Endocr Rev. 18:404-433.

4. Berghout A, Wiersinga WM. 1998 Thyroid size and thyroidal function during pregnancy: an analysis. Eur J Endocrinol. 138:536-542.

5. Berghout A, Endert E, Ross A, Hogerzeil HV, Smits NJ, Wiersinga WM. 1994 Thyroid function and thyroid size in normal pregnant women living in an iodine replete area. Clin Endocrinol. 41:375-379.

6. Yoshimura M, Hershman JM. 1995 Thyrotropic action of human chorionic gonadotropin. Thyroid. 5:425-434.

7. Muller AF, Verhoeff A, Mantel MJ, Berghout A. 1999 Thyroid autoimmunity and abortion: a prospective study in women undergoing in vitro fertilization. Fertil Steril. 71:30-34

8. Roest J, Verhoeff A, van Lent M, Huisman GJ, Zeilmaker GH. 1995 Results of decentralized in vitro fertilization treatment with transport and satellite clinics. Hum Reprod. 10:563-567.

9. Calvo R, Obregon MJ, Escobar del Rey F, Morreale de Escobar G. 1992 The rat placenta and the transfer of thyroid hormones from the mother to the fetus: effect of maternal thyroid status. Endocrinology. 131:357-362.

10. Vulsma T, Gons MH, de Vijlder JJM. 1989 Maternal-fetal transfer of thyroxine in congenital hypothyroidism due to a total organification defect or thyroidal agenesis. N Engl J Med. 321:13-16.

11. Burrow GN, Fisher DA, Larsen PR. 1994 Mechanism of disease: maternal and fetal thyroid function. N Engl J Med. 331:1072-1078.

12. Delange FM. 1995 Endemic cretinism. In: Braverman LE, Utiger RD, eds. The thyroid, 7th ed. Philadelphia-New York: Lippincott-Raven; 756-767.

13. Hershman JM, Higgins HP. 1971 Hydatiform mole-A cause of clinical hyperthyroidism. N Engl J Med. 284:573-577.

14. Berghout A, Endert E, Wiersinga WM, Touber JL. 1988 The application of an immunoradiometric assay of plasma thyrotropin (TSH-IRMA) in molar pregnancy. J Endocrinol Invest. 11:15-19.

15. Wilder RL. 1998 Hormones, pregnancy, and autoimmune diseases. Ann NY Acad Sci. 840:45-50.

16. Formby B. 1995 Immunological response in pregnancy. Its role in endocrine disorders of pregnancy and influence on the course of maternal autoimmune diseases. Endocrinol Metab Clin North Am. 24:187-205.

17. Spencley JC, Mushin D, Barreda Hanson M. 1986 The children of IVF pregnancies: a cohort study. Aust Paediatr J. 22:285-289.

18. Morin NC, Wirth FH, Johnson DH, et al. 1989 Congenital malformations and psychosocial development in children conceived by in vitro fertilization. J Pediatr. 115:222-227.

19. Saunders DM, Lancaster P. 1989 The wider perinatal significance of the Australian in vitro fertilization data collection program. Am J Perinatol. 6:252-257.

20. Brandes JM, Scher A, Itzkovits J, Thaler I, Sarid M, Gershoni Baruch R. 1992 Growth and development of children conceived by in vitro fertilization. Pediatrics. 90:424-429.

21. Saunders K, Spensley J, Munro J, Halasz G. 1996 Growth and physical outcome in children conceived by in vitro fertilization. Pediatrics. 97:688-692.

22. Olivennes F, Kerbat V, Rufat P, Blanchet V, Franchin R, Frydman R. 1997 Follow-up of a cohort of 422 children aged 6 to 13 years conceived by in vitro fertilization. Fertil Steril. 67:284-289.

23. Bowen JR, Gibson FL, Leslie GI, Saunders DM. 1998 Medical and developmental outcome at 1 year for children conceived by intracytoplasmic sperm injection. Lancet. 351:1529-1534. 